\title{
Hydrothermal liquefaction of Nannochloropsis oceanica in different solvents
}

\author{
M.P. Caporgno ${ }^{\mathrm{a}}$, J. Pruvost ${ }^{\mathrm{b}}$, J. Legrand ${ }^{\mathrm{b}}$, O. Lepine $^{\mathrm{c}}$, M. Tazerout ${ }^{\mathrm{d}}$, C. Bengoa $^{\mathrm{a}, *}$ \\ a Departament d'Enginyeria Química, Universitat Rovira i Virgili, Av. Països Catalans 26, 43007 Tarragona, Spain

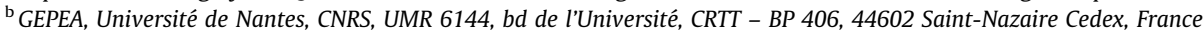 \\ 'AlgoSource SAS, 37 bd de l'Université, CRTT - BP 406, 44602 Saint-Nazaire Cedex, France

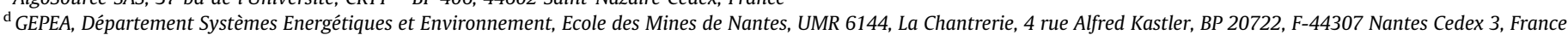

\section{H I G H L I G H T S}

- High bio-oil yields were obtained from wet $N$. oceanica at low temperature.

- High temperatures increase bio-oil yields but decrease their quality.

- Alcohols as co-solvents increase the bio-oil yield from wet biomass.

- Low concentration of alcohols and low temperatures can improve bio-oil yields.
G R A P H I C A L A B S T R A C T

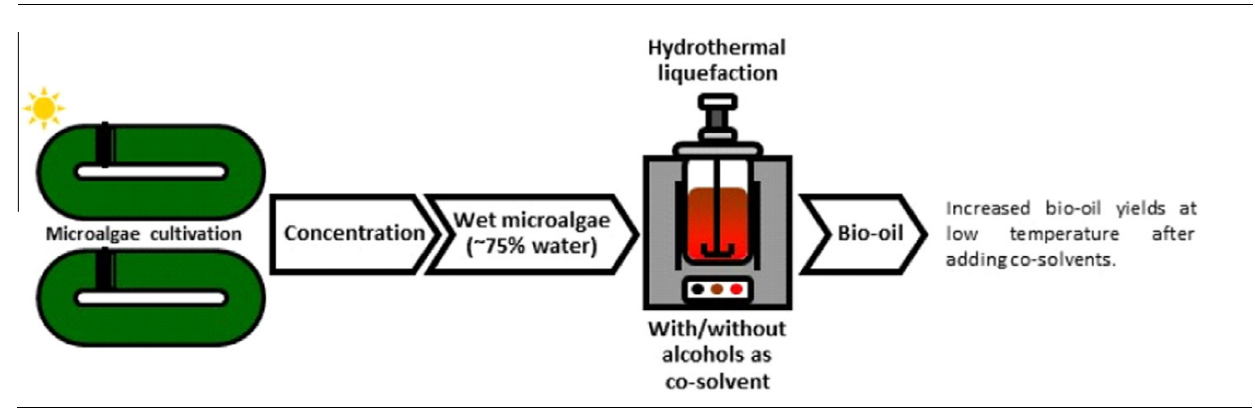

A B S T R A C T

Although the hydrothermal liquefaction is considered a promising technology for converting microalgae into liquid biofuels, there are still some disadvantages. This paper demonstrated that the bio-oil yield can be significantly improved by adding alcohols as co-solvents and carrying out the conversion at mild conditions $\left(<250^{\circ} \mathrm{C}\right)$, but at the expense of a reduced bio-oil quality. By adding ethanol, the bio-oil yields obtained (up to $\sim 60 \%$ ) were comparable to the yield obtained at severe operating conditions using only water as solvent ( $54 \pm 2 \%$ on average), but the quality of the bio-oil was lower. However, the main advantages of the process here described lie in the utilisation of wet microalgae ( $\sim 75 \%$ moisture) and alcohol concentrations which avoid both drying the microalgae and decreasing the amount of microalgae loaded in the reactor.

\section{Introduction}

Microalgae are considered valuable feedstocks for biofuels; they can favourably reduce the demand of fossil fuels and simultaneously alleviate the "food-versus-fuel competition" caused by the production of first-generation biofuels (Pragya et al., 2013).

Several feedstocks characterised by high water content can be converted into a liquid fuel called bio-oil by means of hydrother-

\footnotetext{
* Corresponding author.

E-mail address: christophe.bengoa@urv.cat (C. Bengoa).
}

mal liquefaction (HTL) (López-Barreiro et al., 2013). The HTL is a promising technology for microalgae conversion inasmuch as the reactions take place in the aqueous medium (López-Barreiro et al., 2013), and microalgae are characterised by high water content even after concentration. The elimination of water is highenergy consuming (Pragya et al., 2013). Another advantage of HTL is that lipid, protein, and carbohydrate fractions in microalgae are converted into bio-oil.

The influence of several processing parameters on HTL has been widely evaluated, i.e., reaction temperature, holding time, solid to liquid ratio in the biomass and presence of catalysts (Jena et al., 
2011; Valdez et al., 2012; Reddy et al., 2016). The temperature is a very influential parameter in HTL (Valdez et al., 2012; Li et al., 2014); it affects both the yields and the characteristics of the different fractions obtained during HTL (Li et al., 2014; Gai et al., 2015). Although opposed results have been reported about the influence of the solid to liquid ratio on the bio-oil yield (Valdez et al., 2012), economic and operational aspects may determine the most suitable value of the solid to liquid ratio. According to the literature, solid concentrations under 5\% may lead to negative energy balance, whereas above $15 \%$ cause difficulty in pumping biomass into the reactor at the high pressures required (Valdez et al., 2012). The bio-oil from microalgae is characterised by high viscosity derived from the protein content in microalgae (Guo et al., 2015). Furthermore, the bio-oil is also characterised by high amount of oxygen, which decreases the caloric value and the storage stability (Zhang et al., 2013). Both nitrogen and oxygen contents can be reduced either by upgrading the bio-oil (Guo et al., 2015) or adding catalysts during HTL (Pragya et al., 2013). Recently, it has been reported that processing microalgae with organic solvents can led to better bio-oil quality; some examples are ethanol (Huang et al., 2011; Chen et al., 2012; Reddy et al., 2014; Zhang and Zhang, 2014; Peng et al., 2016), methanol (Patil et al., 2011; Sitthithanaboon et al., 2015) and others (Yuan et al., 2011; Jin et al., 2014a). However, most of these experiments were performed in pure organic solvents or with a negligible amount of water compared to the amount of the organic solvent, which requires low-water content in microalgae. Based on the highwater content in microalgae and the increased the bio-oil production reported from some waste processed in mixtures of water and ethanol or methanol (Yuan et al., 2007; Cheng et al., 2010), processing microalgae in mixtures of solvents is a valuable alternative. Methanol has been used on an industrial for biodiesel production, and it is available at a reasonably low price; however, it is highly toxic and it is currently produced mainly from non-renewable source like natural gas (Reddy et al., 2014). On the other hand, ethanol can be produced from renewable feedstocks (Reddy et al., 2014). Fig. 1 summarises the operating conditions applied by several authors using alcohols as co-solvents for the HTL of microalgae amongst some other substrates (Yuan et al., 2007; Cheng et al., 2010; Patil et al., 2011; Chen et al., 2012; Jin et al., 2014b; Reddy et al., 2014; Zhang and Zhang, 2014; Sitthithanaboon et al., 2015). Processing wet microalgae with organic solvents resulted in increased bio-oil and biodiesel yields (Patil et al., 2011; Chen et al., 2012; Jin et al., 2014a,b; Reddy et al., 2014; Zhang and Zhang, 2014), but the experiments were carried out at high temperatures (Chen et al., 2012) and high con- centration of alcohols (Reddy et al., 2014). The high concentration of alcohol was reached by using dried microalgae (Jin et al., 2014b; Reddy et al., 2014) or loading a low concentration of wet microalgae in the reactor (Patil et al., 2011; Sitthithanaboon et al., 2015) being both alternatives negative from the economic and energetic point of view (Valdez et al., 2012).

The aim of this study is to investigate the HTL of Nannochloropsis sp. in water and in mixtures of water and alcohols. The first part of the experiments evaluates the influence of the temperature on the distribution of products, thus microalgae were processed in water between $240{ }^{\circ} \mathrm{C}$ and $300{ }^{\circ} \mathrm{C}$. Afterwards, the influence of alcohols on the bio-oil characteristics was evaluated by processing microalgae in several alcohol-water mixtures, but using microalgae with high-water content, low temperature and suitable concentration of solids in the reactor.

\section{Materials and methods}

\subsection{Materials}

Nannochloropsis oceanica slurry, $28 \pm 3 \%$ lipid content (\% dry weight), was provided by AlgoSource's (Alpha Biotech, Asserac, France). The frozen slurry was stored at $-15^{\circ} \mathrm{C}$ until required. The total solids (TS) and volatile solids (VS) were analysed as described in (Caporgno et al., 2016A); the TS content was $24.3 \pm 0.3 \%$ and the VS/TS $0.93 \pm 0.01$.

\subsection{Experimental procedure}

\subsubsection{Hydrothermal liquefaction}

The experiments were performed with approximately $100 \mathrm{~g}$ of biomass in a non-stirred batch stainless steel reactor with $1 \mathrm{~L}$ volume capacity (4593, Parr Instruments Co., Moline, IL, USA). The reactor was closed and purged with nitrogen to assure oxygenfree conditions. The temperature was increased until the desired value, and then kept constant during 30 min based on the results reported in the literature for Nannochloropsis biomass (Valdez et al., 2012; Reddy et al., 2016).

The biomass used in first part of the experiments consisted of the microalgae slurry as it was received it, without any addition of water or alcohols. The experiments evaluates the effect of the temperature on the bio-oil, thus several experiments were performed setting the reaction temperatures between $240 \pm 1{ }^{\circ} \mathrm{C}$ and $300 \pm 3{ }^{\circ} \mathrm{C}$ under autogenous pressure conditions. The reactor was not initially pressurised, and the pressure varied from 32 to

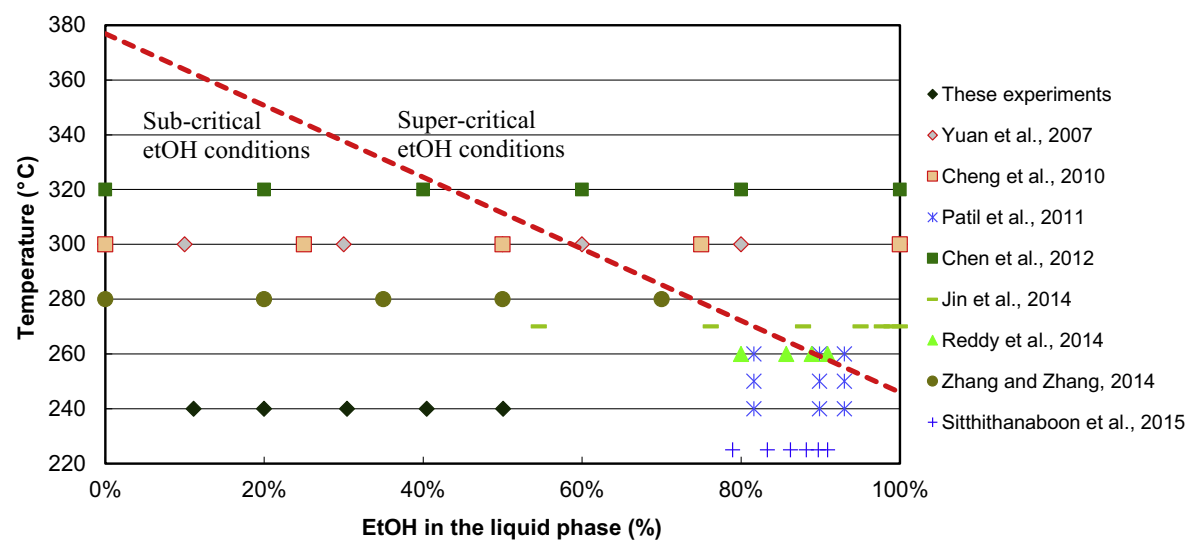

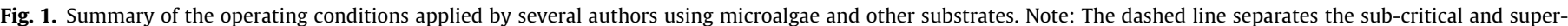

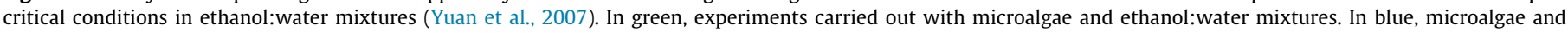
methanol:water mixtures. In red, other substrates and ethanol:water mixtures. 
89 bar when the experiments were performed at temperatures from $240 \pm 1{ }^{\circ} \mathrm{C}$ to $300 \pm 3{ }^{\circ} \mathrm{C}$.

In the second part of the experiments, the reaction temperature was decided around $240{ }^{\circ} \mathrm{C}$ and kept constant during $30 \mathrm{~min}$, under autogenous pressure conditions. The biomass for these experiments consisted of mixtures of alcohols and the microalgae slurry, without any addition of water. The mixtures of ethanol and microalgae slurry were prepared in order to have ethanol:water ratios of $1: 10,3: 10,4: 10,7: 10$ and 10:10 (w/w). Afterwards, an experiment with a methanol:water ratio of 10:10 (w/w) was performed. The reactor was not initially pressurised, and the autogenous pressure varied from 32 to $43 \mathrm{bar}$ when the ration of ethanol increased.

After the $30 \mathrm{~min}$ at the desired temperature, the heating and isolation systems were removed from the reactor, and then the reactor was cooled down to room temperature using an external fan.

For the separation of the different products, the methodology described in a previous work was used (Caporgno et al., 2016B). The total bio-oil, recovered using dichloromethane (DCM), was separated into light and heavy fractions by using hexane to recover the light fraction. The heavy bio-oil fraction was determined by difference between total and light bio-oil fractions. The bio-oil, aqueous products (AP) and solid waste yields were determined according to the Eqs. (1)-(3), and expressed in \% w/w:

Bio-oil yield $(\%)=\frac{\text { Mass of light } / \text { heavy Bio-oil }}{\text { Initial mass of microalgae }} \times 100$

AP yield $(\%)=\frac{\text { Mass of solids dissolved in AP }}{\text { Initial mass of microalgae }} \times 100$

Solid waste yield $(\%)=\frac{\text { Mass of solid residue }}{\text { Initial mass of microalgae }} \times 100$

The number of moles of gas generated in the reactor was calculated using the ideal gas law, taking into account the pressure increase and the volume of free space in the reactor. The mass of gas was then calculated using the average molar mass of the mixture, based on the composition of the gas. The biomass conversion was determined according to the Eq. (4) and expressed in \% w/w:

Conversion $(\%)=\left(1-\frac{\text { Mass of solid residue }}{\text { Initial mass of microalgae }}\right) \times 100$

\subsubsection{Products analysis}

The amount of AP dissolved in the aqueous phase was determined following the procedures for total solids (TS) and volatile solids (VS) described in (Caporgno et al., 2015A). The VS content was also determined in the solid waste with the same procedure.

The components in the gas fraction were determined by a gas chromatography (Two channels micro-GC Agilent technologies $3000 \mathrm{~A}$ ) equipped with thermal conductivity detector (TCD). A molecular sieve column (molecular sieve $5 \AA$, $10 \mathrm{~m} \times 0.32 \mathrm{~mm} \times$ $12 \mu \mathrm{m}$ ) separates $\mathrm{O}_{2}, \mathrm{~N}_{2}, \mathrm{CH}_{4}$, and $\mathrm{CO}$, and a PLOT Q column (PLOT $\mathrm{Q}, 10 \mathrm{~m} \times 0.32 \mathrm{~mm} \times 10 \mu \mathrm{m}$ ) separates of $\mathrm{CO}_{2}$ and light hydrocarbons from $\mathrm{C}_{2} \mathrm{H}_{n}$ to $\mathrm{C}_{4} \mathrm{H}_{n}$.

The bio-oil samples were analysed by chromatography-mass spectroscopy (GC-MS) equipped with a capillary column (SLB$5 \mathrm{~ms}, 30 \mathrm{~m} \times 0.25 \mathrm{~mm} \times 0.25 \mu \mathrm{m}$ ) using a Perkin Elmer Turbo Mass Gold GC-MS. DCM was used as solvent. The GC oven was held at $70{ }^{\circ} \mathrm{C}$ for $1 \mathrm{~min}$, heated to $180^{\circ} \mathrm{C}$ at a rate of $7{ }^{\circ} \mathrm{C} / \mathrm{min}$, then heated to $240{ }^{\circ} \mathrm{C}$ at a rate of $12^{\circ} \mathrm{C} / \mathrm{min}$ and finally $7 \mathrm{~min}$ hold at $330^{\circ} \mathrm{C}$. The composition of the light bio-oil was analysed by GCMS using the method above described but with different solvent, i.e. hexane. The constituents in the bio-oils were identified based on their retention time, and the respective mass spectra were identified from the preinstalled NIST library. The higher heating values of bio-oils (HHVs) were measured using an oxygen bomb calorimeter (6200, Parr Instrument Co., Moline, IL, USA).

The content of $\mathrm{C}, \mathrm{H}, \mathrm{N}$ and $\mathrm{S}$ was measured in microalgae, AP, solid waste and bio-oil using a CE Instruments Flash EA 1112 series elemental analyser.

\section{Results and discussion}

\subsection{Influence of the temperature on $H T L$}

Fig. 2a shows the effects of the temperature on the yields of biooil, AP, solid waste and gas during the HTL of wet microalgae.

The total bio-oil yields were mainly affected when the temperature increased from $240 \pm 1{ }^{\circ} \mathrm{C}$ to $260 \pm 2{ }^{\circ} \mathrm{C}$; further temperature increases did not affect the yield significantly, which averaged $54 \pm 2 \%$ between $260 \pm 2{ }^{\circ} \mathrm{C}$ and $300 \pm 3{ }^{\circ} \mathrm{C}$. Focusing on the light and heavy bio-oil fractions, the results revealed that whereas the heavy fraction increased, the light fraction remained almost unaffected by the changes in the temperature. This behaviour could be a consequence of the nature of both bio-oil fractions. The light biooil mainly contains fatty acids and products from the decomposition of lipids (Valdez et al., 2012), which occurs at mild conditions $\left(<250^{\circ} \mathrm{C}\right)$ (López-Barreiro et al., 2013). On the other hand, the heavy bio-oil contains products generated by decomposition of carbohydrates and proteins (Valdez et al., 2012). Since the decomposition of carbohydrates and proteins requires more severe reaction conditions (López-Barreiro et al., 2013), the fraction of heavy bio-oil was affected by the changes in temperatures (Jena et al.
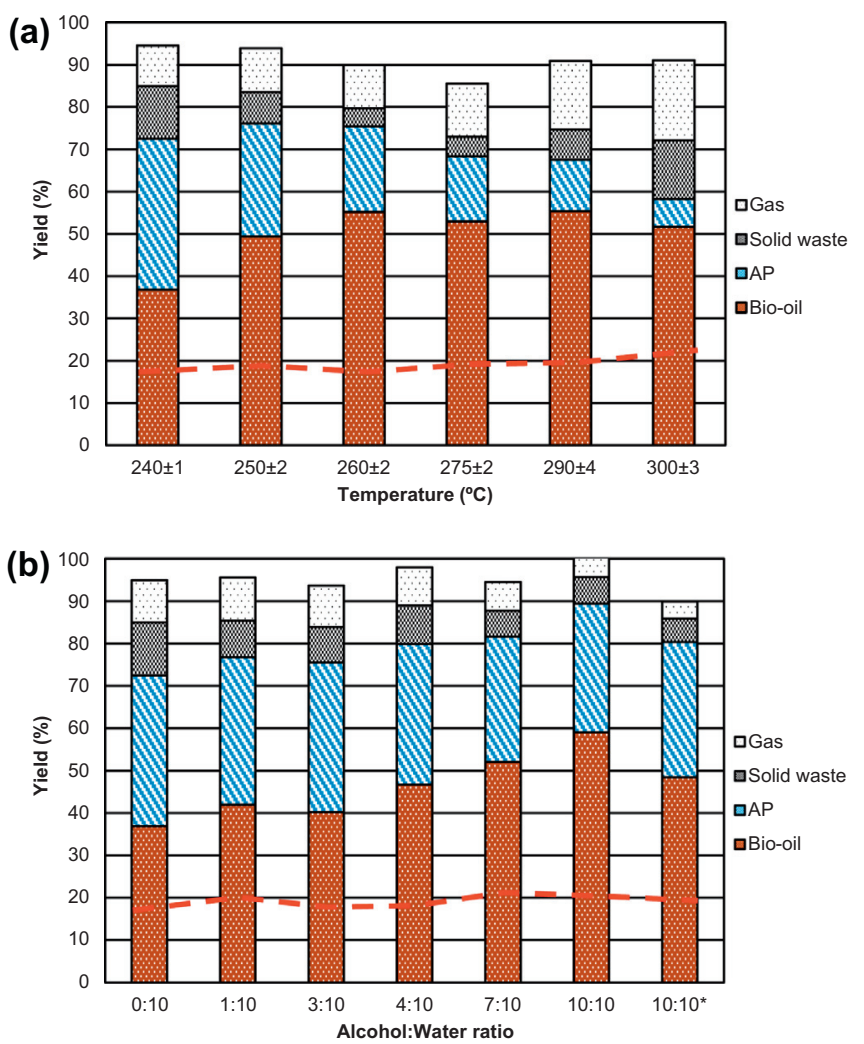

Fig. 2. The effects of the temperature (a) and the addition of co-solvent (b) on the products distribution. Note: The red dashed line indicates the light fraction in biooil. In Fig. 2b, 10:10* represents the results obtained using methanol. (For interpretation of the references to colour in this figure legend, the reader is referred to the web version of this article.) 
2011). Diverse results can be found regarding bio-oil yields from microalgae. The bio-oil yields in the present experiments exceed by far the yields recently reported for the HTL of Nannochloropsis sp. at different temperatures (Reddy et al., 2016), probably due to the high carbohydrate content in the biomass which lead to low bio-oil yields (Biller and Ross, 2011). Other authors reported lower bio-oil yields using the same microalgae species (Tian et al., 2014; Shakya et al., 2015). On the other hand, the bio-oil yields here presented are comparable to the results reported by using Nannochloropsis sp. with similar biochemical composition (Valdez et al., 2012).

Increasing temperatures promoted the conversion of the solid fraction into bio-oil, AP and gases, in accordance with the results reported for the microalgae conversion under sub-critical conditions (López-Barreiro et al., 2013). The amount of compounds solubilised in aqueous phase was the highest at $240{ }^{\circ} \mathrm{C}$ and gradually decreased when the temperature increased, indicating high conversion of the solubilised compounds. The highest AP decreases occurred when the temperature increased up to $260 \pm 2{ }^{\circ} \mathrm{C}$, which is consistent with the increases in the bio-oil yields. The biomass conversion resulted considerable high if compared with the reported in the literature (Reddy et al., 2016), where almost $40 \%$ of the initial Nannochloropsis sp. remained in the solid waste at temperatures between $225^{\circ} \mathrm{C}$ and $275^{\circ} \mathrm{C}$ and 30 min holding time. On the contrary, Valdez et al. achieved similar conversion at mild conditions using the same microalgae species (Valdez et al., 2012). The biomass conversion strongly depends on the biomass characteristics.

A detailed evaluation of the characteristics of the solid revealed a brown-green hue in the filters which suggested the presence of microalgae cells in the solid waste recovered at low temperature. Nannochloropsis species have thick cell walls, which may require high temperatures to promote the biomass conversion (LópezBarreiro et al., 2013). The analysis revealed that further temperature increases affected the solid fraction. At $260 \pm 2{ }^{\circ} \mathrm{C}$, the solids represented around $4 \%$ of the biomass loaded into the reactor; these solids looked like greyish powders similar to ashes and no evidences of microalgae cells were observed. Surprisingly, the solid fraction sharply increased at $290 \pm 4^{\circ} \mathrm{C}$ and $300 \pm 3{ }^{\circ} \mathrm{C}$; in fact, the solid fraction reached its highest yield at $300 \pm 3{ }^{\circ} \mathrm{C}$. The solid recovered had dark particles mixed with greyish powders. Some dark particles were observed at $290 \pm 4{ }^{\circ} \mathrm{C}$, but to a lesser extent. The bio-char is generated when part of the solubilised carbohydrates undergoes to re-polymerisation and carbonisation (Tian et al., 2014; Yang et al., 2015). The solids recovered at $290 \pm 4{ }^{\circ} \mathrm{C}$ and $300 \pm 3{ }^{\circ} \mathrm{C}$ were separated in two different fractions; a greyish powder which was placed in the bottom of the reactor and darkcoloured particles stuck on the reactor walls and mixed with biooil fractions. The increases in microalgae conversion are also evident in Table 1. The high VS/TS in solid and AP at $240 \pm 1^{\circ} \mathrm{C}$ and $260 \pm 2$ confirmed the presence of unreacted microalgae in the solid fraction and the solubilisation of part of the biomass in the aqueous fraction, as consequence of the low temperature (Shakya et al., 2015). The higher the temperature, the lower the VS/TS in both solid and AP, which means that the organic fraction was converted into bio-oil or gas. Temperatures between $225^{\circ} \mathrm{C}$ and $250{ }^{\circ} \mathrm{C}$ cause the thermal denaturing of proteins and their conversion into nitrogen-containing compounds in the bio-oil (López-Barreiro et al., 2013; Guo et al., 2015). Compounds such as formic acid, acetic acid, lactic acid, glycerol, pyroles, indoles and phenols have been found in the aqueous phase elsewhere (Biller and Ross, 2011; Biller et al., 2012). The VS/TS and the elemental analysis of both solid fractions recovered at $290 \pm 4{ }^{\circ} \mathrm{C}$ and $300 \pm 3{ }^{\circ} \mathrm{C}$ revealed that the greyish powder was mainly constituted by ashes from the inorganic fractions of microalgae, similar to the solid fractions recovered at $260 \pm 2{ }^{\circ} \mathrm{C}$ and $275 \pm 3{ }^{\circ} \mathrm{C}$ (Tian et al., 2014). On the contrary, the dark-coloured particles (identified with the superscript b in Table 1) were mainly constituted by organic compounds rich in carbon.

The bio-oil samples were further analysed in order to determine some of their characteristics. The HHVs were similar in all bio-oil samples; the HHV averaged $35.5 \pm 0.5 \mathrm{MJ} / \mathrm{kg}$ in the bio-oil samples produced between $240 \pm 1{ }^{\circ} \mathrm{C}$ and $300 \pm 3{ }^{\circ} \mathrm{C}$, in agreement to the reported in the literature for bio-oil samples from Nannochloropsis (Shakya et al., 2015) and for from other microalgae species (Tian et al., 2014). The qualitative GC-MS analysis of the bio-oil evidenced the complexity of the samples. Bio-oil samples revealed the presence of nitrogenous compounds such as pyrazine, pyridine, indole and amides, mainly generated by chemical reactions and decomposition of proteins. The content of nitrogenous compounds significantly increased when the temperature exceeded $240 \pm 1{ }^{\circ} \mathrm{C}$ (Table 2), which is consistent with the enhanced decomposition of proteins at these temperatures (López-Barreiro et al., 2013). Compared to the $\mathrm{N}$ content in microalgae, it can be observed that the HTL promoted the denitrogenation of microalgae; however, the nitrogen content in the bio-oil from microalgae is still higher than in petroleum (N/C below 0.01) (Tian et al., 2014). The GC-MS analysis of the light bio-oil fraction showed a decreased number of peaks compared to chromatogram corresponding obtained from the heavy bio-oil fraction, which revealed that the nitrogenous compounds constitute mainly the heavy bio-oil fraction as reported by (Valdez et al., 2012). Some of aliphatic hydrocarbons (mainly alkanes and alkenes) and some other aromatic hydrocarbons were identified in the chromatograms. These compounds may be generated from the decomposition of lipids (LópezBarreiro et al., 2013), thus they were already observed in samples produced at the lowest temperature. Their presence at high temperatures indicates stability. In a previous work, the fatty acids originally identified in this microalgae species were eicosapentaenoic (C20:5) and palmitoleic (C16:1), followed by palmitic (C16:0), eicosatetraenoic (C20:4), eicosadienoic (C20:2), oleic (C18:1) and linoleic (C18:2) (Caporgno et al., 2016a). These fatty acids and their esters were also found in bio-oil samples; however, high concentration was only found in bio-oil samples obtained at $240 \pm 1{ }^{\circ} \mathrm{C}$. The reduced fatty acids concentration indicates that they either react or decompose, as it is reported in the literature (Shakya et al., 2015). The identification of amides due to the conversion of oleic and linoleic acids (or their ester) may lead to the decrease in the fatty acid or esters yields. The results in Table 2 show that HTL promotes the deoxygenation of microalgae, but the $\mathrm{O} / \mathrm{C}$ in bio-oil from microalgae was still high and exceeded by far the oxygen content in petroleum $(\mathrm{O} / \mathrm{C}$ around 0.01$)$ (Tian et al., 2014). Both oxygen and nitrogen content are undesirable in bio-oil (Tian et al., 2014).

Regarding the gas fraction, the yields indicated that between $10 \%$ and $20 \%$ of the initial biomass was converted into gaseous products, corresponding these percentages to the lowest and the highest temperatures respectively. The temperature increases caused gas formation, as it has been reported in the literature for Nannochloropsis and other microalgae species (Valdez et al., 2012; Tian et al., 2014; Shakya et al., 2015). Table 3 summarises the main components in the gas samples. As can be observed, the major component in all samples was $\mathrm{CO}_{2}$. Microalgae contain high amount of oxygen, and $\mathrm{CO}_{2}$ formation is one of the preferably ways to remove oxygen during HTL of microalgae (Valdez et al., 2012; López-Barreiro et al., 2013; Tian et al., 2014). The percentage of $\mathrm{CO}_{2}$ strongly decreased when the temperature increased (Brown et al., 2010), and the oxygen removal start also occurring by $\mathrm{O}_{2}$ and $\mathrm{CO}$ production. The percentages of $\mathrm{CH}_{4}, \mathrm{C}_{2} \mathrm{H}_{n}, \mathrm{C}_{3} \mathrm{H}_{n}$ and $\mathrm{C}_{4} \mathrm{H}_{n}$ increased with the temperature, but making a minor contribution to the gas fraction, as observed elsewhere (Brown et al., 2010; Jena et al., 2011). 
Table 1

Elemental analysis of microalgae and solid and AP fractions recovered after HTL at different temperature.

\begin{tabular}{|c|c|c|c|c|c|c|c|}
\hline & & & \multicolumn{4}{|c|}{ Elemental analysis (\% on total solid basis) } & \multirow[t]{2}{*}{ VS/TS } \\
\hline & & & $\mathrm{N}$ & $\mathrm{C}$ & $\mathrm{H}$ & $S$ & \\
\hline \multirow[t]{15}{*}{ Fraction } & \multicolumn{2}{|c|}{ Microalgae } & $7.3 \pm 0.1$ & $50.3 \pm 0.2$ & $7.6 \pm 0.1$ & $0.3 \pm 0.2$ & $0.93 \pm 0.01$ \\
\hline & \multirow[t]{8}{*}{ Solid } & 240 & $5.6 \pm 0.1$ & $53.0 \pm 0.5$ & $5.7 \pm 0.1$ & - & $0.46 \pm 0.01$ \\
\hline & & 250 & $4.6 \pm 0.1$ & $35.0 \pm 1.0$ & $3.8 \pm 0.1$ & - & $0.43 \pm 0.01$ \\
\hline & & 260 & $0.9 \pm 0.1$ & $7.0 \pm 0.4$ & $1.4 \pm 0.1$ & - & $0.15 \pm 0.01$ \\
\hline & & 275 & $0.6 \pm 0.1$ & $7.6 \pm 0.4$ & $1.2 \pm 0.1$ & - & $0.15 \pm 0.01$ \\
\hline & & 290 & $0.5 \pm 0.1$ & $5.6 \pm 0.5$ & $1.0 \pm 0.1$ & - & $0.12 \pm 0.02$ \\
\hline & & $290^{\mathrm{a}}$ & $3.0 \pm 0.1$ & $74.7 \pm 0.3$ & $4.1 \pm 0.2$ & - & $0.85 \pm 0.01$ \\
\hline & & 300 & $0.4 \pm 0.1$ & $7.6 \pm 0.5$ & $0.8 \pm 0.1$ & - & $0.21 \pm 0.03$ \\
\hline & & $300^{\mathrm{a}}$ & $3.4 \pm 0.1$ & $77.6 \pm 0.9$ & $4.9 \pm 0.2$ & - & $0.94 \pm 0.01$ \\
\hline & \multirow[t]{6}{*}{$\mathrm{AP}$} & 240 & $9.8 \pm 0.3$ & $42.9 \pm 1.1$ & $7.1 \pm 0.2$ & - & $0.84 \pm 0.01$ \\
\hline & & 250 & $8.7 \pm 0.1$ & $39.3 \pm 0.4$ & $6.7 \pm 0.1$ & - & $0.78 \pm 0.06$ \\
\hline & & 260 & $5.1 \pm 0.1$ & $29.8 \pm 0.8$ & $4.9 \pm 0.2$ & - & $0.65 \pm 0.05$ \\
\hline & & 275 & $3.4 \pm 0.1$ & $20.8 \pm 0.4$ & $3.5 \pm 0.1$ & - & $0.55 \pm 0.01$ \\
\hline & & 290 & $3.6 \pm 0.1$ & $23.0 \pm 0.6$ & $3.5 \pm 0.1$ & - & $0.55 \pm 0.02$ \\
\hline & & 300 & $2.4 \pm 0.1$ & $15.8 \pm 0.3$ & $2.1 \pm 0.1$ & - & $0.40 \pm 0.01$ \\
\hline
\end{tabular}

a Dark particles.

Table 2

Elemental analysis of the bio-oil recovered after HTL at different temperatures and alcohol:water ratios.

\begin{tabular}{|c|c|c|c|c|c|c|c|c|}
\hline & & \multicolumn{4}{|c|}{ Elemental analysis (\% on total solid basis) } & \multirow[t]{2}{*}{$\mathrm{H} / \mathrm{C}$} & \multirow[t]{2}{*}{$\mathrm{N} / \mathrm{C}$} & \multirow[t]{2}{*}{$\mathrm{O} / \mathrm{C}^{\mathrm{a}}$} \\
\hline & & $\mathrm{N}$ & $\mathrm{C}$ & $\mathrm{H}$ & $\mathrm{S}$ & & & \\
\hline & & $7.3 \pm 0.1$ & $50.3 \pm 0.2$ & $7.6 \pm 0.1$ & $0.3 \pm 0.2$ & 0.15 & 0.14 & 0.55 \\
\hline \multirow[t]{6}{*}{ Temperature } & 240 & $4.8 \pm 0.1$ & $74.5 \pm 0.5$ & $10.1 \pm 0.1$ & - & 0.14 & 0.06 & 0.14 \\
\hline & 250 & $6.5 \pm 0.1$ & $72.7 \pm 0.3$ & $9.7 \pm 0.1$ & - & 0.13 & 0.09 & 0.15 \\
\hline & 260 & $6.7 \pm 0.1$ & $74.1 \pm 0.2$ & $9.5 \pm 0.1$ & - & 0.13 & 0.09 & 0.13 \\
\hline & 275 & $6.5 \pm 0.1$ & $75.1 \pm 0.2$ & $9.6 \pm 0.1$ & - & 0.13 & 0.09 & 0.12 \\
\hline & 290 & $6.0 \pm 0.1$ & $73.8 \pm 0.3$ & $9.4 \pm 0.1$ & - & 0.13 & 0.08 & 0.15 \\
\hline & 300 & $5.5 \pm 0.1$ & $75.3 \pm 0.5$ & $9.5 \pm 0.1$ & - & 0.13 & 0.07 & 0.13 \\
\hline \multirow[t]{6}{*}{ Alcohol:water ratio } & $1: 10$ & $4.9 \pm 0.1$ & $75.2 \pm 0.3$ & $10.2 \pm 0.1$ & - & 0.13 & 0.07 & 0.13 \\
\hline & $3: 10$ & $5.5 \pm 0.2$ & $74.0 \pm 0.1$ & $10.0 \pm 0.1$ & - & 0.14 & 0.07 & 0.14 \\
\hline & $4: 10$ & $6.2 \pm 0.2$ & $72.1 \pm 0.2$ & $9.7 \pm 0.1$ & - & 0.13 & 0.09 & 0.17 \\
\hline & $7: 10$ & $6.6 \pm 0.2$ & $72.2 \pm 0.5$ & $9.7 \pm 0.1$ & - & 0.13 & 0.09 & 0.16 \\
\hline & $10: 10$ & $6.9 \pm 0.1$ & $70.5 \pm 0.1$ & $9.5 \pm 0.1$ & - & 0.14 & 0.10 & 0.18 \\
\hline & $10: 10^{\mathrm{b}}$ & $6.7 \pm 0.1$ & $72.0 \pm 0.1$ & $9.6 \pm 0.1$ & - & 0.13 & 0.09 & 0.16 \\
\hline
\end{tabular}

a Oxygen content calculated by difference.

b Results obtained with methanol.

Table 3

Composition of the gas phase obtained by HTH of microalgae slurry at different temperatures.

\begin{tabular}{|c|c|c|c|c|c|c|c|c|c|}
\hline & & \multicolumn{8}{|c|}{ Gas composition (\%) } \\
\hline & & $\mathrm{H}_{2}$ & $\mathrm{O}_{2}$ & $\mathrm{CH}_{4}$ & $\mathrm{CO}$ & $\mathrm{CO}_{2}$ & $\mathrm{C}_{2} \mathrm{H}_{\mathrm{n}}$ & $\mathrm{C}_{3} \mathrm{H}_{\mathrm{n}}$ & $\mathrm{C}_{4} \mathrm{H}_{n}$ \\
\hline \multirow[t]{6}{*}{ Temperature } & 240 & 0.1 & 1.5 & 0.1 & 0.9 & 97.0 & $<0.1$ & $<0.1$ & 0.3 \\
\hline & 250 & 0.1 & 1.8 & 0.1 & 0.9 & 96.4 & 0.1 & 0.2 & 0.3 \\
\hline & 260 & 0.6 & 1.4 & 0.6 & 2.5 & 93.9 & 0.7 & 0.2 & 0.0 \\
\hline & 275 & 0.5 & 0.6 & 0.5 & 2.0 & 95.5 & 0.4 & 0.4 & 0.1 \\
\hline & 290 & 0.5 & 14.3 & 1.5 & 3.8 & 76.6 & 1.6 & 1.3 & 0.3 \\
\hline & 300 & 0.3 & 9.3 & 2.7 & 2.4 & 75.2 & 3.8 & 1.8 & 4.3 \\
\hline \multirow[t]{6}{*}{ Alcohol:water ratio } & $0: 10$ & 0.1 & 1.5 & 0.1 & 0.9 & 97.0 & $<0.1$ & $<0.1$ & 0.3 \\
\hline & $1: 10$ & 0.1 & 0.2 & $<0.1$ & 1.0 & 97.3 & 0.1 & 0.1 & 1.3 \\
\hline & $3: 10$ & 0.1 & 0.3 & $<0.1$ & 0.9 & 96.2 & 0.2 & $<0.1$ & 2.4 \\
\hline & $4: 10$ & 0.1 & 3.1 & $<0.1$ & 0.7 & 93.5 & 0.1 & $<0.1$ & 2.4 \\
\hline & $10: 10$ & 0.1 & 0.8 & $<0.1$ & 0.8 & 93.2 & 0.2 & 0.2 & 4.8 \\
\hline & $10: 10^{\mathrm{a}}$ & 0.1 & 8.7 & 0.2 & 1.0 & 89.4 & 0.2 & $<0.1$ & 0.3 \\
\hline
\end{tabular}

a Results obtained with methanol.

\subsection{Influence of the addition of alcohol on HTL}

Fig. 2b shows the effects of adding ethanol and methanol as cosolvents during the HTL of microalgae slurry at $240 \pm 3^{\circ} \mathrm{C}$ and 30 min holding time.

The higher the ethanol:water ratio, the higher the bio-oil yield. The effects of ethanol addition are more evident at ratios higher than 3:10. Similar to the results described in Section 3.1., the increase in the bio-oil yields was caused by the increased heavy fraction, since the light fraction (red dashed line) remained almost unaffected by the changes in the ethanol content. The ethanol addition decreased the yield of the solid waste compared to HTL carried out without ethanol; in other words, ethanol addition increased the microalgae conversion. The highest solid conversion were observed at ethanol:water ratio higher than 7:10. The ethanol addition caused AP decreases too. The gas yield barely decreased at 
ethanol:water ratio higher than $7: 10$, being similar to the measured in the experiments performed without ethanol.

Increases in the bio-oil yields were also reported using wet Chlorella pyrenoidosa (approximately $70 \%$ water content) and similar ethanol:water ratios, but higher temperature and considerably long holding times $\left(280^{\circ} \mathrm{C}\right.$ and $120 \mathrm{~min}$ ) (Zhang and Zhang, 2014). Similar results have been recently reported by increasing the ethanol:water ratio, processing Chlorella pyrenoidosa at $300{ }^{\circ} \mathrm{C}$ and 60 min (Peng et al., 2016). The addition of ethanol as co-solvent increased both conversion and bio-oil production from Dunaliella tertiolecta under severe operating conditions $\left(320^{\circ} \mathrm{C}\right.$ ) (Chen et al., 2012). Although other authors reported benefits of ethanol as cosolvent in HTL, (Yuan et al., 2007; Cheng et al., 2010; Jin et al., 2014a; Reddy et al., 2014; Zhang and Zhang 2014), most of these experiments entail high temperature or considerably high amounts of ethanol. Severe reaction conditions cause thermal denaturation of proteins and may decrease the quality of bio-oil (Guo et al., 2015), whereas high concentrations of ethanol requires dried biomass utilisation or an excessively high addition of ethanol may be used. The main advantages of operating conditions in the present experiments are the low temperature and the utilisation of microalgae with high-water content and low concentration of ethanol.

The HHVs resulted in $37.7 \pm 0.1 .38 .1 \pm 0.2 .37 .9 \pm 0.2 .36 .8 \pm 0.4$ $36.1 \pm 0.1$ and $34.6 \pm 0.4 \mathrm{MJ} / \mathrm{kg}$ for bio-oil samples obtained at ratios from 0:10 to 10:10 respectively. In spite of the higher biooil yields obtained when the ethanol:water ratio increases, the HHV was negatively affected. The results presented in Table 2 reveals an increased oxygen content in the bio-oil when the ethanol:water ratio increased, which is consistent with the decrease of the HHV (Tian et al., 2014). Contradictory results are reported in the literature (Chen et al., 2012; Jin et al., 2014b; Peng et al., 2016); however, these results may be attributed to the high temperature during HTL. The high temperatures favour the deoxygenation of bio-oil produced using ethanol as co-solvent (Peng et al., 2016). Measured HHVs in bio-oil samples from Nannochloropsis are similar to the found in the present experiments (Shakya et al., 2015). The denitrogenation was not favoured by the ethanol addition neither.

The qualitative GC-MS analysis of the bio-oil evidenced the complexity of the samples; however, it has been found larger quantities of a relatively small number of compounds than in bio-oils produced without alcohol. The main compounds identified in bio-oils were palmitic (C16:0) and palmitoleic (C16:1) acids. The esters of these acids were found in bio-oils produced with and without ethanol, which means that the acids were not efficiently converted into esters and suggests that the esterification reaction was not favoured by alcohol addition. Some authors have reported high conversion of fatty acids into esters using ethanol; however, they have either used dry microalgae (Jin et al., 2014a), high alcohol:water ratios (Chen et al., 2012; Reddy et al., 2014) or high temperatures (Chen et al., 2012; Jin et al., 2014a) to favour the esterification reactions, or they subjected the bio-oil to subsequent transesterification (Reddy et al., 2014).

The gas composition is summarised in Table 3. Once again, the major component in the gas was $\mathrm{CO}_{2}$. The concentration of $\mathrm{CO}_{2}$ slightly decreased when the ethanol:water ratio increased, but this reduction was not accompanied by $\mathrm{O}_{2}$ and $\mathrm{CO}$ formation. On the contrary, the percentage of $\mathrm{C}_{4} \mathrm{H}_{n}$ increased with the ethanol:water ratio, but making a minor contribution to the gas fraction.

The utilisation of methanol as co-solvent affected the distribution of the products obtained during HTL, as can be observed in Fig. 2b. The solid waste yield was low, which indicates high biomass conversion. Although the biomass conversion and the AP yield with methanol are comparable to the obtained using the same concentration of ethanol or even a lower concentration (ethanol:water ratio 7:10), the bio-oil yield was lower that the obtained with ethanol at 10:10. Based on the light and heavy fractions in bio-oil, it is evident that methanol did not contribute at increasing the heavy bio-oil fraction. Regarding the bio-oil composition, no significant differences were found between the samples produced with ethanol or methanol, as can be observed in Table 2 . The HHV resulted $36.2 \pm 0.1 \mathrm{MJ} / \mathrm{kg}$, similar to the HHV of the bio-oil produce using ethanol in ratio $7: 10$, with comparable elemental composition. The main difference between ethanol and methanol as co-solvent was observed in the composition of the gas fraction; it seems that methanol favoured the deoxygenation by formation of $\mathrm{O}_{2}$.

Comparison between ethanol and methanol as co-solvents for microalgae liquefaction has not been reported in the literature; however, these solvents have been used with woody biomass (Cheng et al., 2010). The authors reported that both alcohols, at alcohols:water ratio of 10:10, increased the biomass conversion and bio-oil yields compared with the HTL using only water as solvent.

\section{Conclusions}

High biomass conversion was obtained by processing $N$. oceanica at mild conditions $\left(<250^{\circ} \mathrm{C}\right)$. More severe operating conditions do not affect the conversion significantly, but strongly affects the distribution of products. Although the bio-oil yields gradually increases by increasing the temperature from $240 \pm 1^{\circ} \mathrm{C}$ to $260 \pm 2{ }^{\circ} \mathrm{C}$, they averaged $54 \pm 2 \%$ between $260 \pm 2{ }^{\circ} \mathrm{C}$ and $300 \pm 3{ }^{\circ} \mathrm{C}$. The quality of the bio-oil was negatively affected. The addition of alcohols as co-solvents allows obtaining bio-oil yield comparable to the obtained at severe operating conditions without alcohols, but decreasing the quality of the bio-oil due to the increased nitrogen and oxygen contents.

\section{Acknowledgements}

Martín Pablo Caporgno thanks the Spanish Ministerio de Educación. Cultura y Deporte for his pre-doctoral scholarship (Ref. AP2012-3726). Financial support for this research was provided by the Spanish Ministerio de Educación y Ciencia and FEDER project CTM2011-23069, and by the GEPEA UMR CNRS 6144. The authors also thank the personnel from Ecole des Mines de Nantes, especially the Energy and Environmental Engineering Department, who kindly help during his research stay.

\section{References}

Biller, P., Ross, A.B., 2011. Potential yields and properties of oil from the hydrothermal liquefaction of microalgae with different biochemical content. Bioresour. Technol. 102, 215-225.

Biller, P., Ross, A.B., Skill, S.C., Lea-Langton, A., Balasundaram, B., Hall, C., Riley, R., Llewellyn, C.A., 2012. Nutrient recycling of aqueous phase for microalgae cultivation from the hydrothermal liquefaction process. Algal Res. 1 (1), 70-76.

Brown, T.M., Duan, P., Savage, P.E., 2010. Hydrothermal liquefaction and gasification of Nannochloropsis sp. Energy Fuels 2010 (24), 3639-3646.

Caporgno, M.P., Trobajo, R., Caiola, N., Ibañez, C., Fabregat, A., Bengoa, C., 2015a. Biogas production from sewage sludge and microalgae co-digestion under mesophilic and thermophilic conditions. Renewable Energy 75, 374-380.

Caporgno, M.P., Olkiewicz, M., Fortuny, A., Stüber, F., Fabregat, A., Font, J., Pruvost, J., Lepine, O., Legrand, J., Bengoa, C., 2016a. Evaluation of different strategies to produce biofuels from Nannochloropsis oculata and Chlorella vulgaris. Fuel Process Technol. 144, 132-138.

Caporgno, M., Clavero, E., Torras, C., Salvadó, J., Lepine, O., Pruvost, J., Legrand, J., Giralt, J., Bengoa, C., 2016b. Energy and nutrients recovery from Nannochloropsis waste via anaerobic digestion and hydrothermal. ACS Sustainable Chem. Eng. Accepted for publication.

Chen, Y., Wu, Y., Zhang, P., Hua, D., Yang, M., Li, C., Chen, Z., Liu, J., 2012. Direct liquefaction of Dunaliella tertiolecta for bio-oil in sub/supercritical ethanolwater. Bioresour. Technol. 124, 190-198. 
Cheng, S., D'cruz, I., Wang, M., Leitch, M., Xu, C., 2010. Highly efficient liquefaction of woody biomass in hot-compressed alcohol-water co-solvents. Energy Fuels 24 4659-4667.

Gai, C., Zhang, Y., Chen, W.T., Zhang, P., Dong, Y., 2015. An investigation of reaction pathways of hydrothermal liquefaction using Chlorella pyrenoidosa and Spirulina platensis. Energy Convers. Manage. 96, 330-339.

Guo, Y., Yeh, T., Song, W., Xu, D., Wang, S., 2015. A review of bio-oil production from hydrothermal liquefaction of algae. Renewable Sustainable Energy Rev. 48, 776-790.

Huang, H., Yuan, X., Zeng, G., Wang, J., Li, H., Zhou, C., Pei, X., You, Q., Chen, L., 2011. Thermochemical liquefaction characteristics of microalgae in sub- and supercritical ethanol. Fuel Process Technol. 92, 147-153.

Jena, U., Das, K.C., Kastner, J.R., 2011. Effect of operating conditions of thermochemical liquefaction on biocrude production from Spirulina platensis. Bioresour. Technol. 102 (10), 6221-6229.

Jin, B., Duan, P., Zhang, C., Xu, Y., Zhang, L., Wang, F., 2014a. Non-catalytic liquefaction of microalgae in sub- and supercritical acetone. Chem. Eng. J. 254, 384-392.

Jin, B., Duan, P., Xu, Y., Wang, B., Wang, F., Zhang, L., 2014b. Lewis acid-catalyzed in situ transesterification/esterification of microalgae in supercritical ethanol. Bioresour. Technol. 162 (2014), 341-349.

Li, H., Liu, Z., Zhang, Y., Li, B., Lu, H., Duan, N., Liu, M., Zhu, Z., Si, B., 2014. Conversion efficiency and oil quality of low-lipid high-protein and high-lipid low-protein microalgae via hydrothermal liquefaction. Bioresour. Technol. 154, 322-329.

López-Barreiro, D., Prins, W., Ronsse, F., Brilman, W., 2013. Hydrothermal liquefaction (HTL) of microalgae for biofuel production: state of the art review and future prospects. Biomass Bioenergy 53, 113-127.

Patil, P.D., Gude, V.G., Mannarswamy, A., Deng, S., Cooke, P., Munson-McGee, S., Rhodes, I., Lammers, P., Nirmalakhandan, N., 2011. Optimization of direct conversion of wet algae to biodiesel under supercritical methanol conditions. Bioresour. Technol. 102 (1), 118-122.

Peng, X., Ma, X., Lin, Y., Wang, X., Zhang, X., Yang, C., 2016. Effect of process parameters on solvolysis liquefaction of Chlorella pyrenoidosa in ethanol-water system and energy evaluation. Energy Convers. Manage. 117, 43-53.

Pragya, N., Pandey, K.K., Sahoo, P.K., 2013. A review on harvesting, oil extraction and biofuels production technologies from microalgae. Renewable Sustainable Energy Rev. 24, 159-171.
Reddy, H.K., Muppaneni, T., Patil, P.D., Ponnusamy, S., Cooke, P., Schaub, T., Deng, S. 2014. Direct conversion of wet algae to crude biodiesel under supercritical ethanol conditions. Fuel 115, 720-726.

Reddy, H.K., Muppaneni, T., Ponnusamy, S., Sudasinghe, N., Pegallapati, A. Selvaratnam, T., Seger, M., Dungan, B., Nirmalakhandan, N. Schaub, T. Holguin, F.O., Lammers, P., Voorhies, W., Deng, S., 2016. Temperature effect on hydrothermal liquefaction of Nannochloropsis gaditana and Chlorella sp. Appl Energy 165, 943-951.

Shakya, R., Whelen, J., Adhikari, S., Mahadevan, R., Neupane, S., 2015. Effect of temperature and $\mathrm{Na}_{2} \mathrm{CO}_{3}$ catalyst on hydrothermal liquefaction of algae. Algal Res. 12, 80-90.

Sitthithanaboon, W. Reddy, H.K., Muppaneni, T. Ponnusamy, S., Punsuvon, V. Holguim, F., Dungan, B., Deng, S., 2015. Single-step conversion of wet Nannochloropsis gaditana to biodiesel under subcritical methanol conditions. Fuel 147, 253-259.

Tian, C., Li, B., Liu, Z., Zhang, Y., Lu, H., 2014. Hydrothermal liquefaction for algal biorefinery: a critical review. Renewable Sustainable Energy Rev. 38, 933-950.

Valdez, P.J., Nelson, M.C., Wang, H.Y., Lin, X.N., Savage, P.E., 2012. Hydrotherma liquefaction of Nannochloropsis sp.: systematic study of process variables and analysis of the product fractions. Biomass Bioenergy 46, 317-331.

Yang, W., Li, X., Li, Z., Tong, C., Feng, L., 2015. Understanding low-lipid algae hydrothermal liquefaction characteristics and pathways through hydrothermal liquefaction of algal major components: crude polysaccharides, crude proteins and their binary mixtures. Bioresour. Technol. 196, 99-108.

Yuan, X.Z., Li, H., Zeng, G.M., Tong, J.Y., Xie, W., 2007. Sub- and supercritical liquefaction of rice straw in the presence of ethanol-water and 2-propanolwater mixture. Energy 32, 2081-2088.

Yuan, X., Wang, J., Zeng, G., Huang, H., Pei, X., Li, H., Liu, Z., Cong, M., 2011. Comparative studies of thermochemical liquefaction characteristics of microalgae using different organic solvents. Energy 36 (11), 6406-6412.

Zhang, J., Chen, W.T., Zhang, P., Luo, Z., Zhang, Y., 2013. Hydrothermal liquefaction of Chlorella pyrenoidosa in sub- and supercritical ethanol with heterogeneous catalysts. Bioresour. Technol. 133, 389-397.

Zhang, J., Zhang, Y., 2014. Hydrothermal liquefaction of microalgae in an ethanolwater co-solvent to produce biocrude oil. Energy Fuels 28 (8), 5178-5183. 